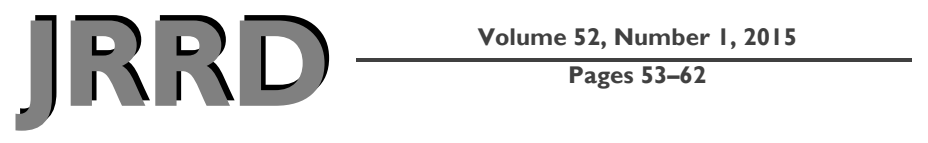

\title{
Identifying obstacles to return to duty in severely injured combat-related servicemembers with amputation
}

\author{
Richard K. Hurley Jr, MD; ${ }^{*}$ Jessica C. Rivera, MD; $^{2}$ Joseph C. Wenke, PhD; ${ }^{3}$ Chad A. Krueger, MD $^{\mathbf{2}}$ \\ Departments of ${ }^{1}$ Orthopaedic Surgery, and ${ }^{2}$ Orthopaedics and Rehabilitation, San Antonio Military Medical Center, \\ Fort Sam Houston, TX; ${ }^{3}$ Department of Regenerative Medicine, Institute of Surgical Research, Fort Sam Houston, TX
}

\begin{abstract}
The capacity of servicemembers with amputation to return to duty after combat-related amputation and the associated disabilities remains largely unknown. The purpose of this study was to examine the disabling conditions and return to duty rates of servicemembers with amputation across all service branches following major limb amputations from September 2001 through July 2011. Pertinent medical information, military occupation status, return to duty designation, disabling conditions, and disability ratings for each servicemember were obtained from the Physical Evaluation Board Liaison Office (PEBLO). Across all service branches, 16 (2\%) servicemembers were found fit for duty (Fit) and allowed to continue with their preinjury occupation. Another 103 (11\%) were allowed to continue on Active Duty (COAD) in a less physically demanding role. More than half $(554,56 \%)$ were determined fully disabled (PEBLO rating > 75); the average disability rating was 73. COAD and Fit Army servicemembers had lower Injury Severity Scores than other servicemembers (17.4, $p=0.009$ and 11.2, $p<0.001$, respectively). Despite improvements in their care and rehabilitation, only $13 \%$ of all servicemembers with amputation are able to return to Active Duty and many have multiple disabling conditions that contribute to a very high level of disability.
\end{abstract}

Key words: Active Duty, amputation, combat, combat-related amputation, disability, disability rating, Injury Severity Score, physician evaluation liaison board, rehabilitation, return to duty.

\section{INTRODUCTION}

Servicemembers who sustained an amputation subsequent to an injury during Operation Iraqi Freedom (OIF),
Operation Enduring Freedom (OEF), and Operation New Dawn (OND) are typically severely injured and require extensive resources during their treatment and rehabilitation [1-2]. While there has been previous research looking at return to duty (RTD) after severe combat-related injuries [3], including amputations [4], analysis of the disabling conditions, disability ratings, and RTD rates between branches of military service for servicemembers sustaining an amputation has not been performed.

RTD rate and Physical Evaluation Board Liaison Office (PEBLO) disability ratings are the best rating scales the military has to determine functionality and disability after severe injury [5-8]. By identifying the most common disabling conditions and assessing how often

\footnotetext{
Abbreviations: $\mathrm{COAD}=$ continuation on Active Duty, Fit $=$ fit for duty, ISS = Injury Severity Score, MAD = military amputation database, $\mathrm{MLA}=$ major limb amputation, $\mathrm{OEF}=$ Operation Enduring Freedom, OIF = Operation Iraqi Freedom, OND = Operation New Dawn, PEBLO = Physical Evaluation Liaison Office, $\mathrm{PR}=$ permanently retired, $\mathrm{RTD}=$ return to duty, SEM = standard error of mean, SWSP = separated with severance pay without disability pay, TDRL = temporarily disabled retired list, ULA = upper-limb amputation.

*Address all correspondence to Richard K. Hurley Jr, MD; Orthopaedic Surgery, San Antonio Military Medical Center, 3851 Roger Brooke Drive, Fort Sam Houston, TX 78234; 210-916-3410; fax: 210-916-7323.
}

Email: richard.k.hurley.mil@mail.mil http://dx.doi.org/10.1682/JRRD.2014.04.0094 
servicemembers with amputation are able to return to duty, areas of emphasis during treatment and rehabilitation can be further refined. Furthermore, improved guidance and expectations can be set for combat-related servicemembers with amputation in terms of their outcomes, abilities, and rehabilitative efforts. The purpose of this study was to determine the most common disabling conditions, the effect of these disabling conditions, and the differences in RTD rates between service branches for those servicemembers with amputation injured during OIF, OEF, and OND.

\section{METHODS}

This study was conducted in accordance with an approved protocol by our institutional review board at the United States Army Institute of Surgical Research. All U.S. servicemembers who sustained a primary, major limb amputation (MLA) from October 1, 2001, through July 30, 2011, were identified by querying a military amputation database (MAD) (the Extremity Trauma and Amputation Center of Excellence; Joint Base Fort Sam Houston, Texas). MLA is defined as an amputation that occurs proximal to the carpals or tarsals of the affected limb [9-10]. Injury characteristics (Injury Severity Score [ISS], level of amputation) and demographic information (age, sex, military rank, branch of military service) were extracted for each servicemember with amputation(s). The MAD query resulted in 1,316 servicemembers who sustained an amputation(s), of which 1,221 had a primary MLA. Data were then crossreferenced by reviewing records within the Department of Defense Trauma Registry (Joint Base Fort Sam Houston, Texas), Armed Forces Health Longitudinal Technology Application, and the Theater Medical Data System in order to obtain the most complete data. Amputation patterns were classified as transtibial, knee disarticulation, transfemoral, lower-limb other (ankle disarticulation, hip disarticulation, hemipelvectomy), and upper-limb amputation (ULA), which includes all ULA subtypes ranging from wrist disarticulation to shoulder disarticulation. Servicemembers with amputation(s) were considered to have multiple amputations if more than one MLA was performed. All servicemembers with amputation(s) were members of either the U.S. Army (Army), the U.S. Air Force (Air Force), the U.S. Marine Corps (Marine), or the U.S. Navy (Navy). Servicemembers in the National Guard or reservists were included in the query if they were Active Duty when the designated injury occurred.

Servicemembers with amputation were queried within their service branch-specific PEBLO database. The PEBLO is a group of medical personnel whose sole responsibility is to establish whether or not injured servicemembers are recovered sufficiently to continue serving on Active Duty status. Once a servicemember has reached a point of maximal medical benefit, those that are capable are placed back on Active Duty status. Servicemembers that warrant further evaluation prior to returning to Active Duty are referred to the PEBLO to determine if a disability exists precluding the servicemember from performing his or her Active Duty role completely. The PEBLO can determine if a servicemember is fit for duty (Fit); eligible for continuation on Active Duty (COAD)/continuation on Active Reserve in a limited capacity or under a new occupational role; needs to be placed on the temporarily disabled retired list (TDRL), which allows for additional recovery time; permanently retired (PR); or should be separated with severance pay without disability pay (SWSP). For those who are unable to return to duty, the medical conditions that preclude them from doing so are called "disabling conditions.” Each disabling condition receives a rating, which reflects the servicemember's percentage decline from functional status. The individual disabling conditions' ratings are combined into an overall disability rating, which determines eligibility for disability benefits once they are no longer on Active Duty status. All military personnel with a final disability rating above 75 are considered to be fully disabled and eligible for the maximum allotted disability payment [10]. RTD status, disabling conditions, disability ratings, military occupation status, and final total disability rating for each servicemember with amputation was gathered from each PEBLO. Disabling conditions were grouped into categories per Cross et al. [11], and the frequency of disability category and the average disability ratings for each were calculated. The effect for each unfitting condition was determined by multiplying the average percentage disability for each disabling condition by the frequency with which each condition occurred [11]. Statistical analysis was performed using Fisher exact test and chi-square to analyze categorical data and analysis of variance to analyze continuous data. Significance was set at $p<0.05$. A linear regression analysis and computation was then performed comparing servicemembers' ISS to their final PEBLO disability rating. 


\section{RESULTS}

A total of 947 servicemembers who sustained an amputation had final PEBLO duty disposition information available at the time of data collection. In total, only 103 (11\%) servicemembers with amputation had a final rating of $\mathrm{COAD}$, and 16 (2\%) servicemembers with amputation had a final duty status of Fit (Table 1). The mean age (24.0 yr), median rank (Enlisted 4) and percentage male (98.4\%) demonstrated that this cohort was demographically consistent with previous studies of wounded servicemembers [3-4,10-11]. There were significantly more Air Force servicemembers with amputation found Fit than in other branches of service $(p<$ 0.001 ), and no Marine or Navy servicemembers with amputation were found Fit. There were 981 total servicemembers with PEBLO disability ratings available at the time information was collected (Table 2). Of all servicemembers with amputation, 56 percent were given a disability rating of 80 or higher, signifying that over half of all servicemembers with amputation were determined to be fully disabled. Across services, Marines were more likely to have a final disability rating of 100 than other service branches. Conversely, mean final PEBLO disability ratings were significantly ( $p<0.001$ ) lower for Marines than for Army servicemembers with amputation; however, when those Marines who were SWSP (by definition these servicemembers receive a disability rating of zero because they are not eligible for disability payments) were removed, there was no significant difference in the mean disability rates among service branches (Table 3). There is no information available that specifically details why servicemembers with amputation would receive a final disability rating of zero.

ISSs were similar across all branches of service for servicemembers with amputation (Table 4) but substantially ( $p=0.05$ ) lower among servicemembers with amputation who were found to be COAD or Fit (16.5, standard error of mean $[\mathrm{SEM}]=0.94)$ compared with those servicemembers with amputation who were TDRL or PR (20.2, SEM = 0.4). Of note, those servicemembers with amputation with the highest mean ISS were actually Marines and Navy servicemembers who were SWSP

Table 1.

Final Physical Evaluation Board Liaison Office duty status.

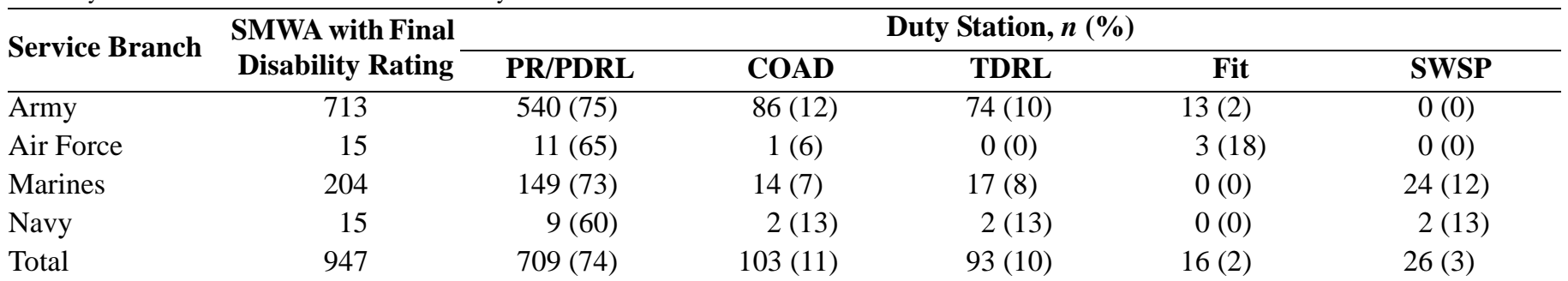

COAD = continuation on Active Duty, Fit = fit for duty, PR/PDRL = permanently retired/permanent disability retired list, SMWA = servicemember with amputation, SWSP = separated with severance pay without disability benefits, TDLR = temporarily disabled retired list.

Table 2.

Final Physical Evaluation Board Liaison Office (PEBLO) disability ratings.

\begin{tabular}{|c|c|c|c|c|c|c|c|c|c|c|}
\hline $\begin{array}{l}\text { Service } \\
\text { Branch }\end{array}$ & $\begin{array}{c}\text { SMWA } \\
\text { with Final } \\
\text { Disability } \\
\text { Rating }\end{array}$ & \multicolumn{9}{|c|}{ Rating Level, $n$ (\%) } \\
\hline Army & 693 & $209(30)$ & $89(13)$ & $103(15)$ & 85 (12) & 85 (12) & $23(3)$ & $98(14)$ & $1(0)$ & $0(0)$ \\
\hline Air Force & 13 & $5(38)$ & $1(8)$ & $1(8)$ & $1(8)$ & $0(0)$ & $1(8)$ & $4(31)$ & $0(0)$ & $0(0)$ \\
\hline Marines & 258 & $98(38)$ & $22(9)$ & $17(7)$ & $14(5)$ & $29(11)$ & $10(4)$ & $38(15)$ & $1(0)$ & $29(11)$ \\
\hline Total & 981 & $316(32)$ & $114(12)$ & $124(13)$ & $103(10)$ & 115 (12) & $34(3)$ & $142(14)$ & $2(0)$ & $31(3)$ \\
\hline
\end{tabular}


Table 3.

Average final Physical Evaluation Board Liaison Office (PEBLO) disability rating by service branch.

\begin{tabular}{lrcccc}
\hline Measure & Army & Air Force Marines & $\begin{array}{c}\text { Marines } \\
\text { (SWSP) }\end{array}$ & Navy \\
\hline Mean & 76.9 & 73.1 & $69.4^{*}$ & 78.2 & 65.0 \\
SEM & 0.8 & 7.5 & 2.1 & 1.6 & 9.0
\end{tabular}

Note: Servicemembers with amputation who were SWSP were removed because their final PEBLO disability was zero.

${ }^{*}$ Significantly lower than Army $(p<0.001)$.

SEM = standard error of mean, SWSP = separated with severance pay without disability pay.

(receiving a disability rating of zero). Excluding those servicemembers with amputation who were SWSP and received a disability rating of zero, the ISS showed very little correlation $\left(R^{2}=0.20\right)$ to combined disability rating (Figure).

On average, each servicemember with amputation was denoted 2.3 disabling conditions by the PEBLO (range: 1 to 8 disabling conditions). As expected, limb amputations accounted for the largest effect in terms of disabling conditions among the servicemembers with amputation. Similarly, 6 of the top 10 most impactful disabling conditions were related to musculoskeletal limb injuries. The most impactful nonmusculoskeletal-related disabling conditions were posttraumatic stress disorder (third overall) and traumatic brain injury (sixth overall) (Table 5).

\section{DISCUSSION}

There has been a substantial number of amputations among U.S. servicemembers involved in OIF, OEF, and OND [3-4,10,12-13]. Depending on severity, treatments rendered, and rehabilitation, many servicemembers are unable to return to Active Duty status following amputation
[3-4,9]. This study attempted to examine the effect of amputation on RTD rates, disability ratings, and duty status among all branches of service. When analyzing RTD rates in general, only 2 percent of all servicemembers with amputation, regardless of service branch, were declared Fit and another 11 percent were declared COAD by the PEBLO. When comparing RTD rates of this study with previous studies from OIF, OEF, and OND, our overall RTD rate of 13 percent was lower yet comparable with those previously published [3-4]. Still, the RTD rate is higher than the 2.3 percent RTD rate reported for servicemembers with amputation by Kishbaugh et al. in 1995 [14]. This difference could represent changes in policy to increase the rate at which servicemembers with amputation return to service, improvements with regards to treatment and rehabilitation of our combat-related servicemembers with amputation receive over the past $20 \mathrm{yr}$, or a combination of these affects.

This study also highlights the difference in RTD rates after amputation between service branches. Recent studies have highlighted variability in RTD rates based on Military Occupational Specialties, and this study affirms varying RTD rates exist between service branches [15]. While it may seem intuitive that each of the service branches provide varying degrees of combat support, each with their own specific set of physical demands, this study underscores different RTD rates between service branches. The difference in RTD rates between service branches may be due in part to the larger number of servicemembers with amputation in the Army and Marines in comparison to the Air Force and Navy. Still, when comparing RTD rates between service branches, Marine and Navy servicemembers with amputation are found to be Fit or COAD at lower rates than both Army and Air Force. In contrast, Air Force members were significantly more likely to be found Fit and RTD status following an amputation (20\%). Policies

Table 4.

Average Injury Severity Score (mean \pm standard error of mean) for final duty status and disability ratings.

\begin{tabular}{lccccc}
\hline $\begin{array}{l}\text { Service } \\
\text { Branch }\end{array}$ & All SMWA & PR/PDRL & COAD & TDRL & Fit \\
\hline Army & $20.5 \pm 0.4$ & $20.4 \pm 0.4$ & $17.3 \pm 1.0$ & $18.7 \pm 1.1$ & $11.7 \pm 1.3$ \\
Air Force & $18.1 \pm 7.7$ & $20.8 \pm 2.4$ & $11.7 \pm 4.1$ & - & $16.0 \pm 3.5$ \\
Marines & $21.4 \pm 0.6$ & $21.9 \pm 0.9$ & $14.2 \pm 2.8$ & $17.6 \pm 2.3$ & - \\
Navy & $19.5 \pm 2.4$ & $19.0 \pm 4.0$ & $29.0 \pm 20.5$ & $23.0 \pm 12.0$ & - \\
\hline COAD = continuation on Active Duty, Fit = fit for duty, PR/PDRL = permanently retired/permanent disability retired list, SMWA = servicemember with amputa- \\
tion, SWSP = separated with severance pay without disability pay, TDRL = temporarily disabled retired list.
\end{tabular}




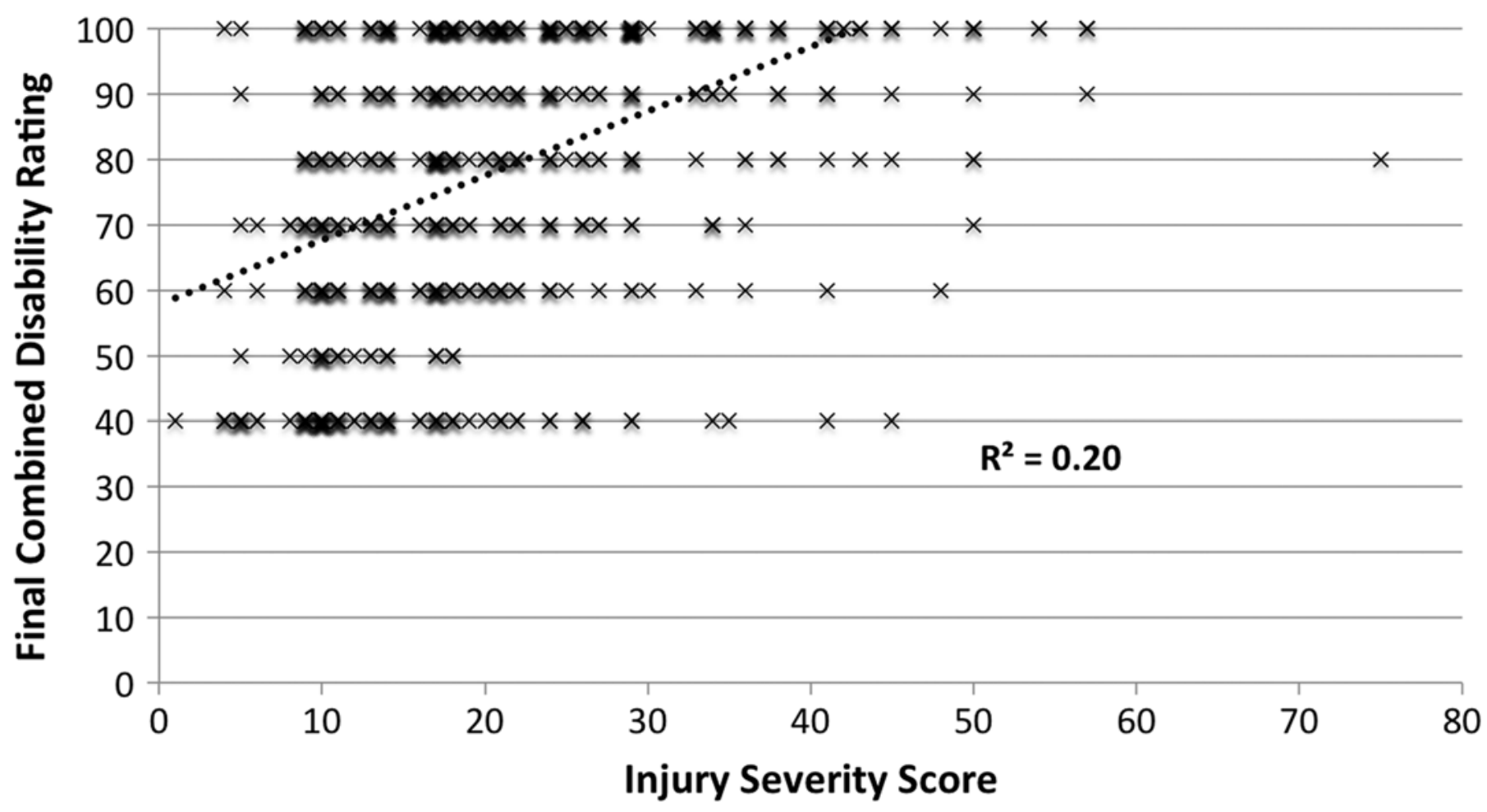

Figure.

Injury Severity Score for all servicemembers with amputation denoting final disability rating. Regression analysis represented by $R^{2}$. Of note, servicemembers with amputation who received disability rating of 0 (those servicemembers with amputation separated with severance pay and not receiving disability benefits) and those with amputation found fit for duty are not included in this graph. This exclusion was made because such designations were thought to reflect policy more than actual disability experienced by servicemembers with amputation.

and procedures, in addition to specific demands for each service branch, must be considered when looking at these data. These policies may help explain the disability ratings and recoveries achieved by some servicemembers with amputation, such as those who were SWSP. All service branches have taken steps to optimize the rehabilitative outcome of their injured servicemembers, and institutions such as the Center for the Intrepid at Fort Sam Houston serve as examples to this. Still, whereas a servicemember who sustained a severely limiting leg injury may be able to operate at a command center without issue, it would seem to be more difficult for that servicemember to perform in a role that included parachuting into and marching through tough terrain. These decisions are made by each servicemember's command and service branch, along with the Physical Evaluation Board, and highlight the individual nature of each case. Service branches may find it helpful to compare and contrast their policies, procedures, and reha- bilitative work in an effort to further improve the RTD rates of servicemembers with amputation.

The exact policies and procedures for each service branch can be found at-

- Army: http://www.apd.army.mil/pdffiles/r635 40.pdf

- Air Force: http://static.e-publishing.af.mil/production/1/af_a1/ publication/afi36-3212/afi36-3212.pdf

- Navy/Marines: http://www.public.navy.mil/asnmra/corb/PEB/ Documents/References/SECNAV\%20INST\%201850 4e.pdf

This study found that the majority of servicemembers with amputation are considered to have a high degree of disability. The mean disability rating was very similar across all branches of service, and over 56 percent of all servicemembers with amputation were determined to have a disability rating of 80 or greater, signifying that the PEBLO found them to be fully disabled [8]. Such severe disability is important to note for multiple reasons. It gives providers, servicemembers with amputation, and their 
Table 5.

Impact scores for disabling conditions for all servicemembers with amputation.

\begin{tabular}{lccr}
\hline \multicolumn{1}{c}{ Disabling Condition } & Frequency & $\begin{array}{c}\text { Mean } \\
\text { Rating }\end{array}$ & Impact \\
\hline Lower-Limb Amputation & 811 & 63 & 51,379 \\
Upper-Limb Amputation & 192 & 75 & 14,390 \\
Posttraumatic Stress Disorder & 174 & 42 & 7,373 \\
Loss of Major Nerve Function & 151 & 30 & 4,560 \\
Arthritis/Decreased Joint Range of Motion & 253 & 17 & 4,361 \\
Traumatic Brain Injury & 157 & 23 & 3,560 \\
Limb Scar & 87 & 25 & 2,140 \\
Loss of Muscle Function & 80 & 25 & 1,980 \\
Facial Injury & 32 & 53 & 1,700 \\
Loss of Hand Function & 58 & 24 & 1,420 \\
Loss of Eye Function & 37 & 33 & 1,230 \\
Abdominal/Pelvic Injury & 25 & 42 & 1,060 \\
Spinal Column Injury & 130 & 6 & 730 \\
Nerve Pain & 21 & 21 & 440 \\
Head Injury & 18 & 24 & 430 \\
Chest injury & 7 & 56 & 390 \\
Back Pain & 21 & 13 & 272 \\
Pain & 27 & 8 & 220 \\
Osteomyelitis & 5 & 38 & 190 \\
Ear Injury & 12 & 6 & 70 \\
\hline Fing & & 6 & \\
\hline
\end{tabular}

Frequency = number of times disabling condition was identified, Impact = calculation made by multiplying frequency with which each disabling condition occurred by mean disability rating that each disability received, Mean Rating = mean of all of individual disability ratings assigned to each specific disabling condition.

support network a realistic idea of what type of recovery they can expect in terms of ability to continue with their previous duties and the amount of support they are likely to require as they recover. While treatment and rehabilitative efforts continue to provide wounded servicemembers with unprecedented advantages compared with previous generations [16-20], this study shows that there still appear to be a cohort of injured patients, specifically, servicemembers with amputation, in which the most advanced technology and rehabilitative efforts are unable to completely mitigate the effects of severe war trauma. It is important to further note in this discussion that no two injuries or wounds are created equally. While two people may be identified as having a transtibial amputation, one amputation may have come after a vascular injury secondary to a penetrating wound that was treated immediately with an amputation that had great soft tissue coverage in an optimal environment. The other amputation may have occurred after a blast injury in which there was significant soft tissue injury, subsequent infection, and a prolonged period of limb salvage prior to undergoing the amputation. These two examples describe different clinical pictures of amputations but would be grouped together for the purposes of this article.

The initial ISS of servicemembers with amputation does not correlate well $\left(R^{2}=0.20\right)$ with outcome and overall disability rating. This finding suggests that the overall disability of servicemembers with amputation is not related to how severely they are initially injured and appears to be more related to the specific orthopedic injuries sustained. For example, one of the patients represented in the Figure rolled his ankle stepping out of a service vehicle, sustaining a closed, tibiotalar dislocation. Despite appropriate treatments and rehabilitative efforts, this patient eventually went on to a transtibial amputation. Another servicemember with transtibial amputation represented in the Figure sustained penetrating injuries to the neck, chest, abdomen, and limbs that resulted in a nonoperative liver laceration, multiple enterotomies to the bowel, a large soft tissue defect to his dominant arm, and numerous retained metallic foreign bodies. Both servicemembers received a disability rating of 40 , but it is clear that both servicemembers had much different initial injury severities (ISS of 1 vs 41, respectively). These two examples represent the extremes of these data but highlight what Cross et al. demonstrated when looking at the overall disability of 456 injured servicemembers who underwent PEBLO evaluation between 2001 and 2005: orthopedic injuries drive the disability of injured servicemembers [11]. Such a finding appears to be even more evident when looking at severely wounded servicemembers who have sustained an amputation. A servicemember with amputation with a higher ISS does not necessarily go on to have more disability than one with a lower ISS since most servicemembers with amputation were found to be severely disabled with the exception of the small percentage of servicemembers who were able to return to duty. The focused nature and acuity in treatment and rehabilitation now offered to all servicemembers may also influence the similarity in overall disability seen between those servicemembers with amputation with large and small ISS.

Cross et al. also found that 76 percent of all disabling conditions reported from combat-related wounds involved the musculoskeletal system [11]. This study supports their findings: 6 of the top 10 most impactful disabling conditions found among these servicemembers with amputation involved the musculoskeletal system. While lower-limb amputations and ULAs are to be expected considering this cohort, loss of major nerve function and arthritis/decreased joint motion rank as the fourth and fifth most impactful disabilities. Such disabilities are potentially critical when considering that the servicemembers in this study have already 
lost a limb. Losing function of another limb could have important implications during rehabilitation, affect their function and ability to reintegrate into society [21], and may lead the servicemember to consider an amputation of another limb [22]. Posttraumatic stress disorder and traumatic brain injury were also very impactful disabling conditions. While such conditions are quite common among those injured in combat, it should be recognized that such a condition is likely to hamper the rehabilitative efforts of these injured servicemembers [23]. As such, rehabilitative efforts for these servicemembers should include some aspect that deals directly with these conditions in order to maximize their outcomes.

This study has a number of limitations. First, this is a retrospective analysis that utilized a number of data sources. As such, it is vulnerable to the biases and potential errors that are innate with such studies. The outcome data used in this study are relatively short-term since they only represent a servicemember's function at the point at which a decision was made on his or her status by the PEBLO (which may be months or years after their initial injury). It is possible that some of the servicemembers with amputation who were found to be severely disabled and retired actually went on to gain good long-term function.

While the PEBLO results provide an assessment of military-specific outcomes with regard to RTD and conditions that preclude return to Active Duty status, each branch of service (Army, Air Force, and Navy/Marines) has slightly different policies regarding the designation of a disability percentage and use of disability payments. For example, some servicemembers, specifically within the Marines, received a disability percentage designation of zero. This does not indicate that the amputation was not recognized as a disability. The injury and amputation are identified as service disqualifying conditions; however, the rating percentage is not emphasized as is the determination of the disqualifying or unfitting condition. By virtue of the servicemember's medical retirement, he or she is designated to be a disabled veteran, which is of paramount importance for matriculation in the Department of Veterans Affairs healthcare system even if the military disability percentage per service-specific policy is zero. More so, receiving a disposition of COAD, PR, TDRL, or Fit does not mean that each individual can perform the same tasks. COAD could mean returning to a desk job for some servicemembers, whereas it could mean participating in more strenuous labor for another. These gradients of function within each disposition are difficult to define because each individual case will have different limitations and expectations within their final disposition. Furthermore, the level of training and desire to return to duty for each injured servicemember may also have an effect on their disability. One study found that members of the Special Forces were almost 10 times more likely to deploy after undergoing an amputation than the general amputee population [24]. Such findings could indicate that specific patient populations have either intrinsic or extrinsic factors that help them minimize disability from injury. However, the authors are unaware of any studies that have identified such factors within a military population and this study did not attempt to do so either.

This study did not utilize patient-reported outcome measures such as the Short Musculoskeletal Function Assessment or 36-Item Short Form Health Survey questionnaires [25]. The purpose of this study was not to negate work that may have been performed by previous authors but merely to highlight what information we do have available with respect to combat-related individuals with amputation and their corresponding disability ratings. The disability ratings reported for servicemembers with amputation do not reflect a percentage based on function. In fact, the disability ratings for medical separation are based on percentages for diagnoses and are not based on any functional assessment of an individual (e.g., the percent rating for a single transtibial amputation is the same across all patients, independent of function). It is also important to note that an individual's desire to remain on Active Duty plays a role in his or her final disposition. It is likely that servicemembers with an amputation who strongly desire to return to a Fit status will obtain that status at a higher rate than servicemembers with an amputation who have little desire to stay in the military. Furthermore, there may be financial incentives that could influence a servicemember's desire to remain on Active Duty or seek permanent retirement. COAD will result in a servicemember returning to his or her original salary, whereas PR may entitle the servicemember to disability benefits/pay in addition to whatever the salary of his or her next employment may be. As mentioned, each service branch has different policies and guidelines and each individual case has multiple variables to be considered. In addition, all injuries are not created equal. Some amputations are certainly more severe than others, and it was impossible to qualify each specific injury that was evaluated by this study. All of these factors should be considered when analyzing the RTD rates of this population. As such, these results may not translate well to the civilian 
population because there seem to be numerous differences between civilian and military trauma patients in terms of their potential incentives to return to work in addition to their treatment and rehabilitative options. One of the strengths of this study was the fact that all of the amputations within the $10 \mathrm{yr}$ time frame were included; therefore, this mitigated the selection bias that is present in smaller single-center studies. Still, it is impossible to say if these data will remain constant over time. Technologies, policies, and rehabilitation abilities change with time and there is likely to be a variation in the disability found among servicemembers with amputation because of these changes. At a later date, it would be interesting to further evaluate the disabilities of servicemembers with amputation during distinct time periods of these conflicts to further illustrate the distinct patterns found within those periods.

\section{CONCLUSIONS}

Despite continued improvements in their care and rehabilitation, only 13 percent of all servicemembers with amputation are able to return to Active Duty, with merely 2 percent being able to return to their original occupation. Army and Air Force servicemembers with amputation appear to return to duty at higher rates than Marine and Navy servicemembers, and those who do return to duty tend to have fewer or less severe associated injuries. The majority of servicemembers with amputation have multiple disabling conditions that contribute to a very high level of disability and may make rehabilitation more challenging. Much like the general population of injured servicemembers, 6 of the top 10 most impactful disabling conditions in this population are related to musculoskeletal injuries and two of the other most impactful disabilities are conditions that can negatively affect a servicemember's ability to regain physical and emotional function.

\section{ACKNOWLEDGMENTS}

\author{
Author Contributions: \\ Study concept and design: J. C. Wenke, C. A. Krueger. \\ Acquisition of data: J. C. Wenke, C. A. Krueger. \\ Analysis and interpretation of data: R. K. Hurley, J. C. Rivera, \\ J. C. Wenke, C. A. Krueger. \\ Drafting of manuscript: R. K. Hurley, C. A. Krueger. \\ Critical revision of manuscript for important intellectual content: \\ R. K. Hurley, J. C. Rivera, J. C. Wenke, C. A. Krueger.
}

Statistical analysis: C. A. Krueger.

Administrative support: R. K. Hurley.

Study supervision: J. C. Rivera, J. C. Wenke, C. A. Krueger.

Financial Disclosures: The authors have declared that no competing interests exist.

Funding/Support: This study was unfunded at the time of manuscript preparation.

Institutional Review: This study commenced after being approved by the United States Army Institute of Surgical Research Institutional Review Board.

Disclaimer: The opinions or assertions contained herein are the private views of the authors and are not to be construed as official or reflecting the views of the Department of the Army, Department of Defense, or the U.S. Government. This work was prepared as part of their official duties and, as such, there is no copyright to be transferred.

\section{REFERENCES}

1. Fleming M, Waterman S, Dunne J, D’Alleyrand JC, Andersen RC. Dismounted complex blast injuries: Patterns of injuries and resource utilization associated with the multiple extremity amputee. J Surg Orthop Adv. 2012;21(1): 32-37. [PMID:22381508]

2. Blough DK, Hubbard S, McFarland LV, Smith DG, Gambel JM, Reiber GE. Prosthetic cost projections for servicemembers with major limb loss from Vietnam and OIF/OEF. J Rehabil Res Dev. 2010;47(4):387-402. [PMID:20803406] http://dx.doi.org/10.1682/JRRD.2009.04.0037

3. Cross JD, Stinner DJ, Burns TC, Wenke JC, Hsu JR; Skeletal Trauma Research Consortium (STReC). Return to duty after type III open tibia fracture. J Orthop Trauma. 2012; 26(1):43-47. [PMID:21885998] http://dx.doi.org/10.1097/BOT.0b013e31821c0ec1

4. Stinner DJ, Burns TC, Kirk KL, Ficke JR. Return to duty rate of amputee soldiers in the current conflicts in Afghanistan and Iraq. J Trauma. 2010;68(6):1476-79.

[PMID:20068483]

http://dx.doi.org/10.1097/TA.0b013e3181bb9a6c

5. US Army Personnel Separations. Physical evaluation for retention, retirement, or separation. Army Regulation 63540. Washington (DC): Department of the Army; 2006 [updated 2012 Mar 20; cited 2010 Oct 10]. Available from: http://armypubs.army.mil/epubs/pdf/r635_40.pdf

6. U.S. Army. Medical services: Standards of medical fitness. Army Regulation 40-501. Washington (DC): Department of the Army; 2007 [updated 2011 Aug 4; cited 2010 Oct 1]. Available from:

http://armypubs.army.mil/epubs/pdf/r40 501.pdf

7. U.S. Army. Medical services: Patient administration. Army Regulation 40-400. Washington (DC): Department of the Army; 2014 Available from: http://armypubs.army.mil/ epubs/pdf/r40 400.pdf 
8. Veterans Benefits Administration. Book C, schedule for rating disabilities. Title 38 Code of Federal Regulations. Washington (DC): Department of Veterans Affairs; [updated 2014 Jul 7; cited 2010 Oct 1]. Available from: http://www.benefits.va.gov/WARMS/

9. Krueger CA, Wenke JC, Ficke JR. Ten years at war: Comprehensive analysis of amputation trends. J Trauma Acute Care Surg. 2012;73(6 Suppl 5):S438-44. [PMID:23192067] http://dx.doi.org/10.1097/TA.0b013e318275469c

10. Stansbury LG, Lalliss SJ, Branstetter JG, Bagg MR, Holcomb JB. Amputations in U.S. military personnel in the current conflicts in Afghanistan and Iraq. J Orthop Trauma. 2008;22(1):43-46. [PMID:18176164] http://dx.doi.org/10.1097/BOT.0b013e31815b35aa

11. Cross JD, Ficke JR, Hsu JR, Masini BD, Wenke JC. Battlefield orthopaedic injuries cause the majority of long-term disabilities. J Am Acad Orthop Surg. 2011;19(Suppl 1):S1-7. [PMID:21304041]

12. Dougherty AL, Mohrle CR, Galarneau MR, Woodruff SI, Dye JL, Quinn KH. Battlefield extremity injuries in Operation Iraqi Freedom. Injury. 2009;40(7):772-77. [PMID:19450798] http://dx.doi.org/10.1016/j.injury.2009.02.014

13. Potter BK, Scoville CR. Amputation is not isolated: An overview of the US Army Amputee Patient Care Program and associated amputee injuries. J Am Acad Orthop Surg. 2006;14(10 Spec No.):S188-90. [PMID:17003197]

14. Kishbaugh D, Dillingham TR, Howard RS, Sinnott MW, Belandres PV. Amputee soldiers and their return to active duty. Mil Med. 1995;160(2):82-84. [PMID:7783923]

15. Belisle JG, Wenke JC, Krueger CA. Return-to-duty rates among US military combat-related amputees in the global war on terror: Job description matters. J Trauma Acute Care Surg. 2013;75(2):279-86. [PMID:23887560] http://dx.doi.org/10.1097/TA.0b013e31829bb777

16. Fergason J, Keeling JJ, Bluman EM. Recent advances in lower extremity amputations and prosthetics for the combat injured patient. Foot Ankle Clin. 2010;15(1):151-74.

[PMID:20189122] http://dx.doi.org/10.1016/j.fcl.2009.10.001

17. Behrend C, Reizner W, Marchessault JA, Hammert WC. Update on advances in upper extremity prosthetics. J Hand Surg Am. 2011;36(10):1711-17. [PMID:21971060] http://dx.doi.org/10.1016/j.jhsa.2011.07.024

18. Harvey ZT, Loomis GA, Mitsch S, Murphy IC, Griffin SC, Potter BK, Pasquina P. Advanced rehabilitation techniques for the multi-limb amputee. J Surg Orthop Adv. 2012; 21(1):50-57. [PMID:22381511]

19. Harvey ZT, Potter BK, Vandersea J, Wolf E. Prosthetic advances. J Surg Orthop Adv. 2012;21(1):58-64.

[PMID:22381512]
20. Pasquina PF, Bryant PR, Huang ME, Roberts TL, Nelson VS, Flood KM. Advances in amputee care. Arch Phys Med Rehabil. 2006;87(3 Suppl 1):S34-43, quiz S44-45. [PMID:16500191] http://dx.doi.org/10.1016/j.apmr.2005.11.026

21. Holbrook TL, Anderson JP, Sieber WJ, Browner D, Hoyt DB. Outcome after major trauma: 12-month and 18-month followup results from the Trauma Recovery Project. J Trauma. 1999;46(5):765-71, discussion 771-73. [PMID:10338392] http://dx.doi.org/10.1097/00005373-199905000-00003

22. Quon DL, Dudek NL, Marks M, Boutet M, Varpio L. A qualitative study of factors influencing the decision to have an elective amputation. J Bone Joint Surg Am. 2011; 93(22):2087-92. [PMID:22262380] http://dx.doi.org/10.2106/JBJS.J.01998

23. Melcer T, Walker GJ, Sechriest VF 2nd, Galarneau M, Konoske P, Pyo J. Short-term physical and mental health outcomes for combat amputee and nonamputee extremity injury patients. J Orthop Trauma. 2013;27(2):e31-37.

[PMID:22495531] http://dx.doi.org/10.1097/BOT.0b013e3182517e1c

24. Krueger CA, Wenke JC. Initial injury severity and social factors determine ability to deploy after combat-related amputation. Injury. 2014;45(8):1231-35. [PMID:24613612] http://dx.doi.org/10.1016/j.injury.2014.02.008

25. Doukas WC, Hayda RA, Frisch HM, Andersen RC, Mazurek MT, Ficke JR, Keeling JJ, Pasquina PF, Wain HJ, Carlini AR, MacKenzie EJ. The Military Extremity Trauma Amputation/Limb Salvage (METALS) study: Outcomes of amputation versus limb salvage following major lower-extremity trauma. J Bone Joint Surg Am. 2013;95(2):138-45.

[PMID:23324961]

http://dx.doi.org/10.2106/JBJS.K.00734

Submitted for publication April 3, 2014. Accepted in revised form November 14, 2014.

This article and any supplementary material should be cited as follows:

Hurley RK Jr, Rivera JC, Wenke JC, Krueger CA. Identifying obstacles to return to duty in severely injured combat-related servicemembers with amputation. J Rehabil Res Dev. 2015;52(1):53-62. http://dx.doi.org/10.1682/JRRD.2014.04.0094

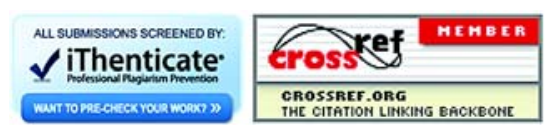


